\title{
FACTOR ANALYSIS OF SUICIDAL RISK AND PROTECTIVE MECHANISMS OF PEDAGOGICAL STUDENTS IN KAZAKHSTAN
}

\author{
Mukhtar Tolegen ${ }^{1}$, Bibikul Utegenova ${ }^{2}$, Botagoz Baymuhambetova ${ }^{2,3}$, Tatyana Smagliy ${ }^{2}$, \\ Saule Berdenova ${ }^{4}$, Bagytzhan Alshanova ${ }^{2}$, Tatyana Pchelkina ${ }^{2}$, \\ Gauhar Balgabaeva $^{2}$ \& Saule Baizhanova ${ }^{2}$ \\ ${ }^{1}$ East Kazakhstan State University named after S. Amanzholova, Ust-Kamenogorsk, Kazakhstan \\ ${ }^{2}$ Kostanay State Pedagogical University, Kostanay, Kazakhstan \\ ${ }^{3}$ Kostanay Social Technical University named after the Academician Z. Aldamzhar, Kazakhstan \\ ${ }^{4}$ Kostanay State University named after A. Baitursynova, Kostanay, Kazakhstan
}

received: 8.1.2020;

revised: 13.2.2020;

accepted: 31.8 .2020

\section{SUMMARY}

Background: The study aims to identify the underlying causes, risks and protection factors in the field of suicidal behavior among pedagogical students to understand and reduce the prevalence of victimization and suicide in the education system.

Subject and methods: The analysis of suicidal risk factors and protective mechanisms among pedagogical students is carried out based on the results of psychological testing, correlation and factor analysis.

Results: Results of the study show that the following two factors greatly influence suicidal behavior among pedagogical students. Firstly, there is "Psychological (personal) risk factor of suicidal behavior", which combines indicators of destructive personality of students, leading to suicidal behavior. Secondly, there is "Conflict socio-environmental risk factor of suicidal behavior" that combines indicators of disharmonious upbringing and disharmonious relationships with the immediate environment. Moreover, in stressful situations, most future teachers from the "risk group" use non-constructive strategies of the protective mechanisms "projection" and "regression" and have a high level of an overall tension index of these mechanisms.

Conclusions: It is found that the suicidal factors, characteristic for pedagogical students, do not differ from the suicidal factors characteristic for students from other specialties. These factors affect a large number of pedagogical students (41.5\%). There might be several risk factors at once, which increases the likelihood of suicidal thoughts and actions. The results of the study can be used to predict and prevent suicidal behavior among pedagogical students and increase the effectiveness of the psychological services of universities.

Key words: pedagogical students - protective mechanisms - factor analysis - suicidal behavior - suicide

\section{INTRODUCTION}

Currently, suicide and suicidal attempts are recognized worldwide as the most urgent problem. The number of suicides among adolescents and young people is growing every year, and this category of the population is the highest-risk group in both developing and developed countries (Bertolote et al. 2005). In recent years, Kazakhstan has consistently been among the states with an unfavorable suicidal situation.

Of particular relevance is the problem of suicide among students, since this particular social group is the most progressive, informed, mobile part of society - the state's fund (Nusenova 2012). Teacher plays an important role in the increment of intellectual assets in modern society. It is the teacher, who is called upon, in accordance with the challenges of the time, to do the following:

- effectively respond to the educational needs of students;

- create conditions for the formation of creative thinking;

- develop the intellectual potential of the younger generation, which tomorrow will set the state's development vector (Information and legal system of regulatory legal acts of the Republic of Kazakhstan, 2019).
Without exaggeration, it can be said that the future of the nation directly depends on the level of professional competence of the teacher, on his/her social, mental and physical health (Nuriev et al. 2013). That is why the problem of suicidal behavior among students, and especially pedagogical students, causes great concern for the future of the state.

Many personal, socio-environmental, clinical, economic identified risk factors of suicidal behavior are characteristic for the entire student population. Moreover, many authors highlight the following anti-vital experiences as the risk factors for suicidal behavior of students, namely: hopelessness; callousness; abandonment; uselessness; loneliness (Peltzer et al. 2017). Others highlight the demographic factor, considering student age to be one of the main suicidal periods. The system of personal beliefs, life values and attitudes is unstable and insufficiently formed. The lack of life experience contributes to rash acts, suicide (Kholmogorova et al. 2009).

Nevertheless, the educational environment of the pedagogical university has its own peculiarities and causes great creative and mental stress. First of all, there are increased requirements for the personality of the future teacher, his/her intellectual and human qualities (Myrzakhanova et al. 2014). 
Based on the foregoing, there is a need to identify risk factors that are relevant specifically for pedagogical students.

There is a need to systematize a wide range of risk factors and help to avoid stereotypical assumptions about students' suicidal behavior. In addition, the results obtained will help to better understand the existing problems of future teachers, and in more detail and in the early stages to identify people at risk.

In order to mitigate the effects of risk factors, it is also important to study protective factors, since they increase the person's resistance (Vahia et al. 2011).

Thus, in combination with information on the prevalence of risk factors, data on protective factors can be taken into account when adjusting the mechanisms for organizing the educational process at a university. University leadership can use the results to improve the mechanism for managing education, as well as to fill in gaps in the university's psychological service system.

After analyzing statistical data and studying the spread of suicidal behavior among young people, it can be said that this adverse phenomenon increases in many countries of the world.

In the scientific world, there is more than enough evidence that students who have attempted suicide often make subsequent attempts over the next three months (Eaton et al. 2010). It should be noted that girls are more likely to commit suicidal attempts than boys, and boys are more likely to complete their suicidal intentions (Cramer et al. 2017). It is recognized that suicide attempts sometimes increase because of widely publicized suicides or fictitious portrayals of suicidal behavior (Cash \& Bridge 2009).

The experience of international researchers shows that in case of mental disorders, namely depression, schizophrenia, disorders due to the use and abuse of certain substances and antisocial behavior are significant risk factors for the occurrence of suicidal mood among students (Said et al. 2013). This is confirmed by the results of a study that has been conducted among students of universities in Islamabad, which shows that $67.3 \%$ of students at risk of suicidal behavior show a high level of depression, which is due to problems with the family, with studies and financial difficulties (Fazal et al. 2012).

However, there is sufficient scientific evidence that mentally healthy individuals can commit suicide under the pressure of certain circumstances. Psychological autopsy of young people who died as a result of suicidal actions shows that in most cases suicide is preceded by social, stressful and situational factors. Such factors include difficult financial situation, participation in religious practices, social characteristics of education, interpersonal conflicts, rape, cyberbullying, etc. (Peltzer et al. 2017). Students of non-traditional sexual orientation are especially at high risk of suicides (Goldblum et al. 2015). An argument in favor of this statement is that homophobic attitudes in society create serious social and personal stress factors that increase the likelihood of suicidal behavior (PerezBrumer et al. 2017).

Several studies have found a significant correlation between Internet addiction, suicidal thoughts, and selfharming behavior (Zimmerman et al. 2016). According to American psychologists (Messias et al. 2011), playing video games or surfing the Internet for more than 5 hours a day are associated with a risk of depression and suicidal thoughts. This problem is also urgent at present for Kazakhstan in connection with a number of cases of suicide in which relatives of the victims indicate an involvement of the latter in the activities of such thematic groups as "Blue Whale" on the social network "Vkontakte" (Abil et al. 2016).

Some researchers often note certain personal traits as factors provoking suicidal behavior (such as emotional instability, perfectionism, impulsivity, and aggressiveness) (Hamilton \& Schweitzer 2000, Wang et al. 2014, Loftis et al. 2019).

Thus, the analysis of international research on the student suicide issue has shown a wide range of different situations, circumstances and factors that increase the risk of student suicide. However, despite numerous studies of suicidal behavior among students, many aspects are not well studied. There are gaps in knowledge about the frequency of suicides among pedagogical students, their personalization differences. To understand the risk of suicide in this group of the population, as well as to implement and improve effective intervention strategies, an analysis of risk factors and protective mechanisms is conducted among pedagogical students.

Purpose of the study is to identify causes as well as risk and protection factors of suicidal behavior among pedagogical students in order to reduce victimization and suicide in the education system.

\section{SUBJECTS AND METHODS}

Research work took place between December 2018 and May 2019. The study involved students of the following universities of Kazakhstan:

- Kostanay State Pedagogical University named after U. Sultangazin;

- Students of the social and psychological faculty of the Kostanay State University named after A. Baitursynov;

- Students of the faculty of psychology, pedagogy and culture of East Kazakhstan State University named after S. Amanzholov.

In total, there were 528 students (270 girls and 258 boys) of 1-4 years of study. The average age was 18-22 years.

An empirical study of risk factors for suicidal behavior among pedagogical students is carried out in three stages: 
- Stage 1 - identification of the "risk group";

- Stage 2 - diagnosis of the relationship between risk factors and protective mechanisms for the development of suicidal behavior in students from a "risk group";

- Stage 3-determining the structure of risk factors of suicidal behavior in pedagogical students.

To identify the risk group, the authors have used: Suicidal Behaviors Questionnaire (SBQ-14) revised by Linehan (1996). SBQ-14 measures the following behavioral domains: suicidal behavior in the past, suicidal thoughts about the future, and threats of suicide in the past, prospective suicide attempts in the future and the likelihood of death from suicide in the future. The authors have included students in the "risk group" if students' points have exceeded limit values on one or more psychopathological assessment scales.

To study the socio-environmental risk factors of suicidal behavior of pedagogical students, the following approved psychometric assessment toolkit is used: an adapted Family Environment Scale (FES) technique proposed by Rudolf and Bernice Moos (1986). This technique is designed to assess the social climate in families of all types. Young's diagnostic questionnaire is used (YDQ) for Internet Addiction (Young 1998). The authors' questionnaire, "Satisfaction with the chosen profession and teaching methods", consists of 20 questions. The questionnaire includes special questions regarding the following:

- Motives in choosing a teacher's profession;

- Satisfaction with the quality of teaching disciplines;

- Satisfaction with the organization of the educational process;

- Difficulties in mastering educational programs.

The adaptation of the methods in the Kazakh language was carried out by experts of the Republican Scientific and Practical Center for Mental Health of the Republic of Kazakhstan. The experts brought in line the versions of translation and retranslation. During the preparatory phase, several meetings were held to revise the following:

- format of the methods;

- the translation;
- whether the methods are adequately depicted in the English version;

- whether the methods are adapted to the cultural characteristics of the country.

To determine the clinical factors of suicidal risk in "risk group" students, the authors use the following:

- The Russian version of the SF-36 Health Status Survey questionnaire, developed by Ware et al. (1993). This questionnaire assesses the quality of human life determined by health conditions;

- An adapted version of the Holmes \& Rahe (1967) stress test;

- Barratt's impulsivity scales (Barratt et al. 1999);

- Perfectionism of Hewitt et al. (2006).

To assess the leading mechanisms of psychological protection, the authors have used the adapted test questionnaire "Life Style Index" of Plutchik et al. (1979).

When processing empirical data, to generalize and systematize the results, the following methods have been used. Namely, standard statistical analysis (standardization of data, methods of correlation and factor analysis), based on Statistica 6.0 computer program.

\section{RESULTS}

In accordance with the research algorithm, the results of surveying 528 students (270 girls and 258 boys of 1-4 courses) have been processed. Out of the examined, 219 people have been added to "risk group" (41.5\%), including 154 girls $(29.2 \%)$, 65 boys (12.3\%).

Mean values (X) of suicidal behavior risk have been compared and thus first-year students have higher average values of the risk of suicidal behavior $(X=9.37)$ than students of the second $(X=3.76)$, third $(X=4.1)$ and the fourth $(X=9.28)$ courses. Student's t-test makes it possible to talk about the presence of significant differences in the risk indicators of suicidal behavior among first-year students and second-year students $(t=3.58$, at $\mathrm{p}<0.01)$ and third-year students $(\mathrm{t}=3.58$, at $\mathrm{p}<0.01)$, except for fourth-year students (no significant statistical differences have been found $(\mathrm{t}=1.75$, at $\mathrm{p}>0.01)$. Thus, it can be argued that first-year students are more suicidal than second-year and third-year students.

Table 1. Distribution of pedagogical students by the level of risk of suicidal behavior and suicidal activity by courses (years of study)

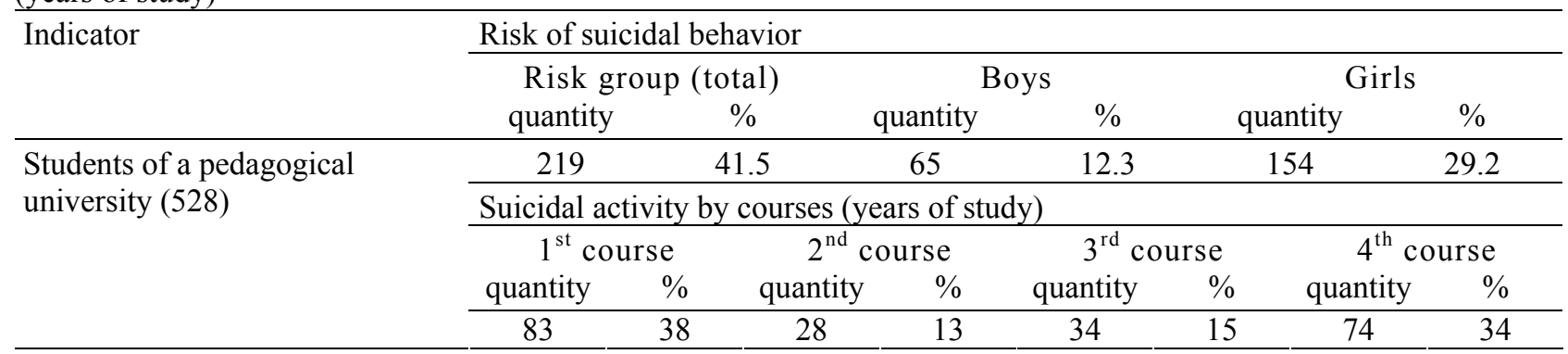

Results according to the Suicidal Behaviors Questionnaire (SBQ-14) of Linehan (1996) 
The risk level of suicidal behavior of second-year students is significantly lower than the risk levels of third-year students $(\mathrm{t}=2.66$, with $\mathrm{p}<0.05)$ and fourthyear students $(\mathrm{t}=3.43$, with $\mathrm{p}<0.01)$. Similarly, the risk level of suicidal behavior in third-year students is significantly lower than the risk level of suicidal behavior in fourth-year students $(\mathrm{t}=3.01$, with $\mathrm{p}<0.01)$.

Consequently, it is found that the $1^{\text {st }}$ course $(38 \%)$ and $4^{\text {th }}$ course $(34 \%)$ are the most suicidal periods of study at a pedagogical university (Table 1 ).

Analysis of risk factors show that more than half of students at risk have a low degree of stress tolerance, which makes them more vulnerable (results on the "stress tolerance" scale of Holmes and Rahe). The ability to overcome negative life events is weakened by such personal destructions as impulsiveness (results on the BIS scale), perfectionism (results on the perfectionism scale of Hewitt and Flett), character accentuation (results on the questionnaire "Character Accentuation" by Leonhard, Schmishek). At the same time, the vast majority of "risk group" students have low indicators of the quality of life, which is associated with psychological health (the results according to the questionnaire "SF-36 Health Status Survey”). Zang's ZSAS and Beck Depression Scales (BDI-I) confirm mental health problems, where symptoms of anxiety and depressive disorders of mild to moderate intensity were found in more than half of students at risk. In addition, the results of the study show that almost every third student of the risk group has an increased family conflict and, as a result, reduced indicators of family cohesion (according to the B. Moos FES method).

It should be noted that the choice of the profession of a teacher for students from the "risk group" is due to random circumstances. Nevertheless, there are few students who are not satisfied with the choice of profession and the quality of teaching (the results of the questionnaire "Satisfaction with the chosen profession and teaching methods"). The percentage of students with computer addiction is not large either. Basically, students at risk are characterized by a stage of enthusiasm, "sticking" to addiction, the so-called attachment (the results of screening diagnostics according to Young's Diagnostic questionnaire).

A high level of the general index of protective mechanisms' intensity is specific for "risk group" students, from the individual and personal perspectives. Moreover, the vast majority of students from a "risk group" in stressful situations often use non-constructive protective mechanisms: "projection" and "regression". The data are presented in Figure 1.

To identify the relationship between suicidal behavior and the identified risk factors, the authors have performed a correlation analysis, where the risk of suicidal behavior has the closest positive relationship on 4 scales:

- "conflict" ( $\mathrm{r}=0.896$ at $(\mathrm{p} \leq 0.05)$;

- "perfectionism" ( $\mathrm{r}=0.857$ at $(\mathrm{p} \leq 0.05)$;

- "anxiety" ( $\mathrm{r}=0.731$ at $(\mathrm{p} \leq 0.05)$;

- "depression" ( $\mathrm{r}=0.712$ at $(\mathrm{p} \leq 0.05)$.

There is as well a significant negative relationship of suicidal behavior with three indicators:

- "stress tolerance" ( $\mathrm{r}=-0.867$ at $(\mathrm{p} \leq 0.05)$;

- "psychological protection" $(\mathrm{r}=-0.823$ at $(\mathrm{p} \leq 0.05)$;

- "cohesion" ( $\mathrm{r}=-0.813$ at $(\mathrm{p} \leq 0.05)$.

The remaining indicators (with the exception of "quality of teaching" and "computer addiction", as no reliable relationships have been found $(p>0.05))$ have correlated with suicidal behavior on moderate and low levels. The data are presented in Figure 2.

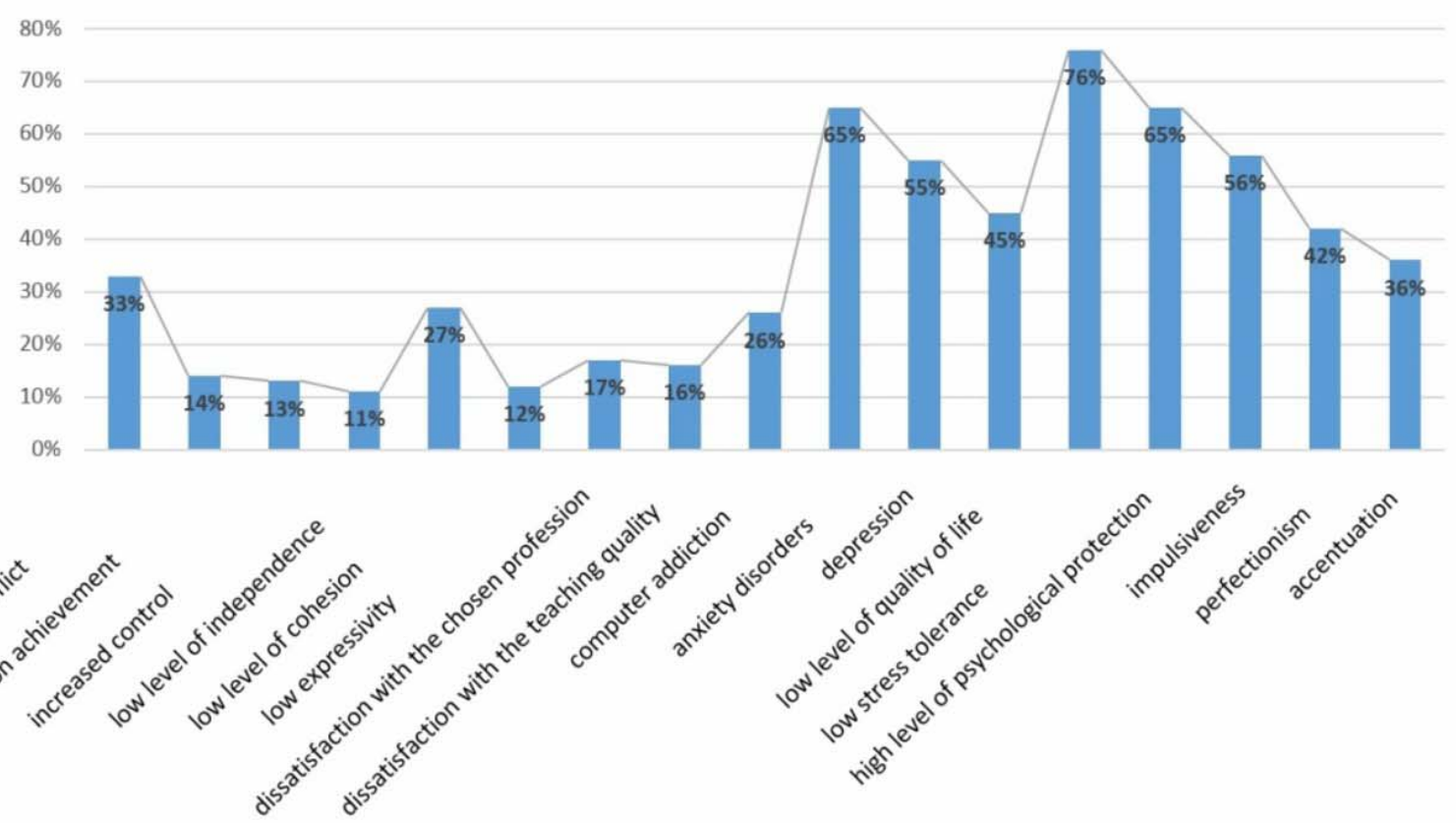

Figure 1. Risk factors of suicidal behavior of pedagogical students 


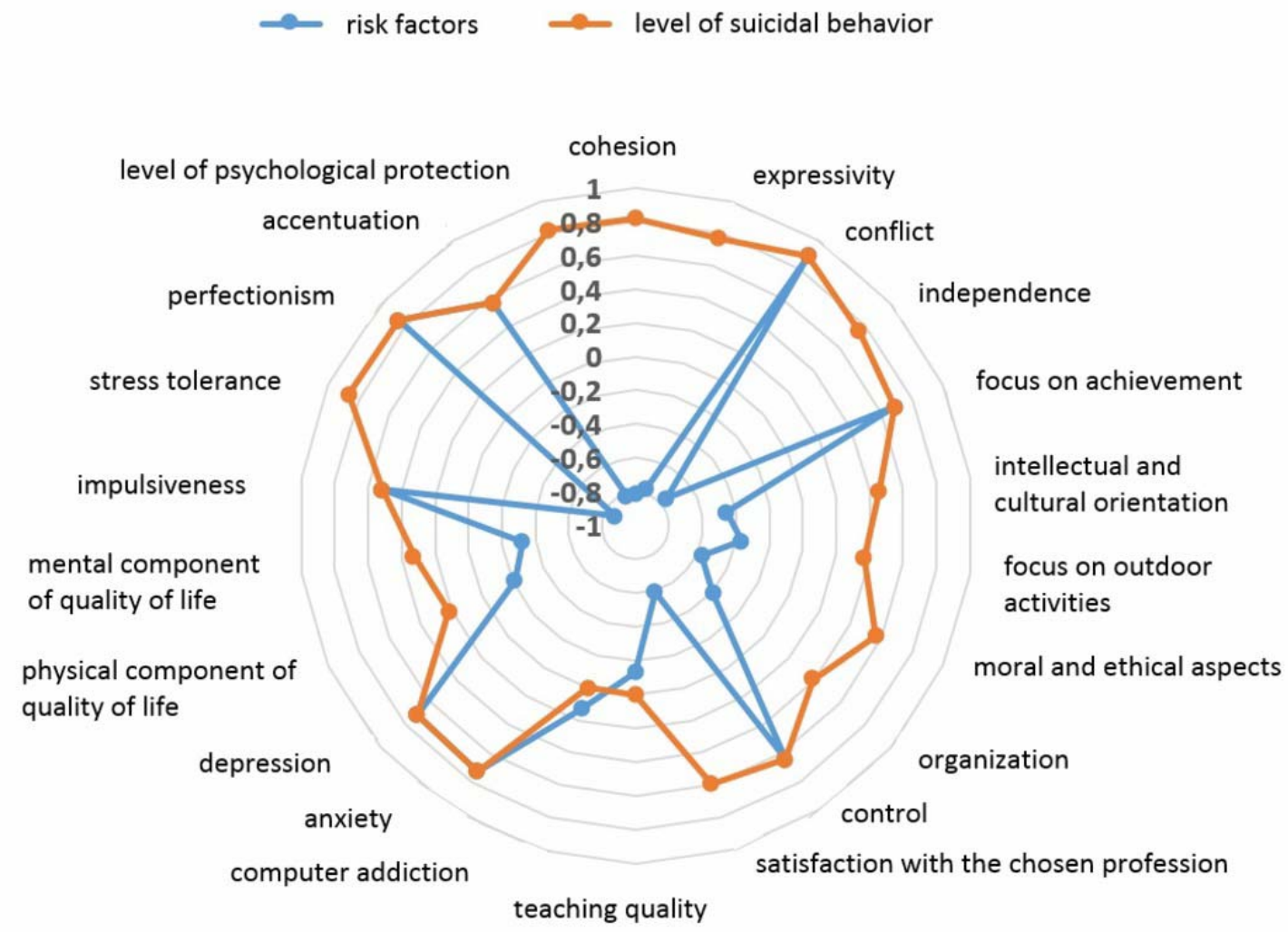

Figure 2. Correlation of socio-environmental, clinical and personality factors with the risk of suicidal behavior of pedagogical students (numbers indicate the correlation coefficient)

Table 2. Factors of suicidal behavior of "risk group" students

\begin{tabular}{llr}
\hline Factor & Methodology, indicators & \multicolumn{2}{c}{$\begin{array}{c}\text { Value of factor's } \\
\text { indicator }\end{array}$} \\
\hline F1 - 29.4\% & "Stress Resistance Scale" - stress test of Holmes \& Rahe (1967) & -0.969 \\
"Psychological & "The scale of perfectionism", "Perfectionism" questionnaire of Hewitt et al. (2006) & 0.929 \\
(personal) risk factor & "Defense Mechanisms Inventory" - "Life Style Index", Plutchik et al. (1979) & -0.867 \\
of suicidal behavior" & Mental health component scale, questionnaire "SF-36 Health Status Survey" (1993) & -0.854 \\
& Zung (1971) Self Rating Anxiety Test & 0.798 \\
& Beck Depression Inventory (BDI-I) (Beck et al. 1961). & 0.771 \\
& Barratt's impulsivity scale (Barratt et al. 1999). & 0.644 \\
& Leonhard (1976) Accented Persons & 0.634 \\
F2-27.8\% & "Conflict scale", Family Environment Scale (FES) methodology & 0.912 \\
"Conflict-generating & "Cohesion scale", FES methodology & -0.886 \\
socio-environmental & "Achievement Orientation Scale", FES methodology & 0.758 \\
factor of suicidal & "Control scale", FES methodology & -0.654 \\
behavior" & "Expressivity scale", FES methodology & -0.645 \\
& "Satisfaction with the chosen profession", questionnaire designed by the authors & -0.611 \\
\hline
\end{tabular}

To determine the relationships between selected factors and the risk of suicidal behavior, the authors have used the method of factor analysis. As an initial set of variables (that characterize the risk of suicidal behavior), the final indicators are considered that have been obtained while using a diagnostic study. As a result, 2 main factors are identified, the total dispersion of which covers $57.2 \%$ of the entire sample. The most powerful of the obtained factors - "Factor I" (dispersion 0.29), combines 8 variables.
The variables that form "Factor II" can be generally called "Conflict-generating social and environmental risk factors of suicidal behavior". The factor's title can be justified by the features of factor's variables. The "conflict" indicator (0.912) is the most pronounced, revealing the presence of conflicts in families of "risk group" students. "Cohesion" (-0.886) indicates the tendency to emotional detachment, inconsistency of behavior, indifference to others. The composition of the factors is presented in Table 2 . 


\section{DISCUSSION}

Analysis shows that suicidal behavior is a serious problem among pedagogical students in Kazakhstan. In fact, high percentage $(41.5 \%)$ of students has been included in a "risk group", since their psychometric indicators have exceeded the threshold values of the scales used in the study. The study reveals significant gender differences in suicidal behavior. There are more girls $(16.9 \%)$ than boys in the "risk group". This gender composition of the "risk group" (with the dominance of girls) confirms the assumption of a number of scientists that girls have a higher risk of suicidal thoughts and intentions than boys (Cramer et al. 2017). Concerning suicidal activity in relation to a particular year of study (course), the indicators state that the risk of suicide is significantly higher among first-year students than among graduates (Delara \& Woodgate 2015). While in this study, on the contrary, the difference between 1 st year and 4th year of study is not significant. The main reasons for suicidal thoughts and intentions (according to the surveyed graduates) are as follows:

- Recognition of the wrong choice of their future profession;

- Low prestige of the "teacher" in modern Kazakhstan society;

- Low wages;

- The prospect of working in the village (if one studies according to the rural quota), etc.

According to the study results, the identified socioenvironmental, clinical, and individual risk factors play a significant role in the emergence of suicidal behavior in future teachers. Statistically significant relationships have not been found between suicidal behavior and such indicators as "quality of teaching" and "computer addiction". At the same time, the authors have studied students' satisfaction with professional program's quality. The latter allows drawing some conclusions about the educational process in a university as well as about the psychological difficulties of students in the learning process. The relation of "computer addiction" to the risk of suicidal behavior among pedagogical students has been revealed in studies (Messias et al. 2011, Abil et al. 2016; Zimmerman et al. 2016). In contrast, the authors of the current study explain a paradox that might cause the absence of such a relation. The latter has been also described by Swedish scientists Durkee et al. (2011) while exploring the spread of suicidal thoughts on the Internet. The paradox is that on the one hand, people suffering from mental illness are already predisposed to the dangers posed by the Internet. On the other hand, they also tend to receive the help that the Internet provides. This discrepancy might be due to the different interests of students, the different content of the websites they visit, etc. In any case, this paradox emphasizes the need for further research in this area.
The results of factor analysis show that the risk of suicidal behavior of pedagogical students is represented by two factors. The first factor $(29.4 \%)$ combines indicators of destructive personality traits of "risk group" students, leading to a risk of suicidal behavior. In this factor, the "stress resistance" indicator (-0.969) has a high influence on the formation of suicidal behavior among pedagogical students. A low stress resistance makes a person more vulnerable, therefore students from the "risk group" are forced to spend most of their energy and resources on the fight against negative psychological states because of stress.

Wasserman believes that stressful factors affect people with a suicidal orientation in such a way that they are not able to use effective and adequate coping strategies (Wasserman et al. 2005). Such assumptions are confirmed by data obtained using the questionnaire "Life Style Index" of Plutchik et al. (1979). Thus, "risk group" students use non-constructive protective strategies "projection" and "regression" in stressful situations. That is, they attribute their unacceptable feelings to other people or avoid anxiety by moving to earlier stages of libido development. In addition, a high level of protective psychological mechanisms indicates unresolved conflicts and problems. Students' assessments of the quality of life have been analyzed. Thus, psychological problems have been detected. Namely, there is an imbalance between high values of the "physical component" (83.4) and reduced values (60.7) of the "mental component". Students' low assessments of their mental health indicate fatigue, a decrease in vital activity due to deterioration in the emotional state.

In the current study, perfectionism (42\%) is typical for the majority of "risk group" students, which significantly increases the risk of suicidal behavior. This indicator is consistent with the study of Hamilton \& Schweitzer (2000). Moreover, the results of the current study confirm the views of a number of authors that perfectionist beliefs about insolvency lead to mental disorders of an individual (Bell et al. 2010). Mental disorders such as depression or anxiety, increased fatigue, and deterioration of emotional state have been detected in almost every second "risk group" student.

It is typical for $56 \%$ of "risk group" students to act in stressful situations impulsively, without sufficient conscious control, under the influence of external circumstances or because of emotional state. Students with a pedantic accentuation (anxious-dubious) (15\%), are increasingly anxious, cautious and indecisive; with excitable (explosive) accentuation (10\%) - impatient and irritable; with "stuck" accentuation (8\%) - boring, suffer from imaginary injustice.

The second factor $(27.8 \%)$ combines indicators of disharmonious education and disharmonious relations with the immediate environment. In this factor, the "conflict" indicator has the greatest impact, which indicates the presence of constant quarrels and scandals in the family environment of "risk group" 
students. The said is supported by reduced indicators of "cohesion", which can be either a cause or a consequence of conflicts.

An analysis of previous studies indicates that the identified risk factors for suicidal behavior of pedagogical students in Kazakhstan are characteristic for the student population of many countries. Thus, similar personality destructions that provoke suicidal behavior (impulsiveness and aggression) are found in studies of Wang et al. (2014) (among Chinese students). Studies of Hewitt and Flett (2006) focus on a high correlation between suicidal behavior and a high level of perfectionism among Australian students. Studies of Gençöz and Or (2006) emphasize that the family environment and family relations are a significant risk factor for Turkish students, as well as for pedagogical students in Kazakhstan.

Finally, the authors of the current study found that the identified risk factors for suicidal behavior of pedagogical students are consistent with risk factors of Polish students enrolled in the educational program "Pedagogy and Psychology" at the University of Białystok. For these students, personal and family risk factors are the most common (Sacharewicz \& Maciorkowska 2005). This might be due to the personalization differences of pedagogical students that are a special subpopulation.

Nevertheless, the current study is somewhat different from other studies in the following aspects. Namely, the identified risk factors for suicidal behavior do not represent the properties of a separate risk factor, but of several risk factors in aggregate.

Given that the total effect of the risk of suicidal behavior can be enhanced under the influence of several factors, numerous studies have revealed the combination of all kinds of risk factors for suicidal behavior among students:

- poor social contacts and insufficient coping skills of Chinese students (Tang \& Qin 2015);

- the presence of a partner;

- mental breakdown;

- substance abuse;

- unwanted homosexual or heterosexual intercourse;

- mental disorders;

- social networks and other as risk factors in Hamadan Medical University students (Poorolajal et al. 2017).

\section{CONCLUSIONS}

Based on the factor analysis of risk indicators of suicidal behavior, it can be concluded that suicidal factors that are typical for pedagogical students do not differ from the suicidal factors typical for other students. The study shows that $41.5 \%$ of pedagogical students are affected by risk factors. It is also found that there might be several risk factors simultaneously, which increases the likelihood of suicidal thoughts and actions. Thus, the identified risk factors of suicidal behavior among pedagogical students should trigger the occurrence of the relevant psychological assistance to the students.

\section{Acknowledgements: None}

\section{Conflict of interest: None to declare.}

\section{Contribution of individual authors:}

Mukhtar Tolegen, Bibikul Utegenova, Botagoz Baymuhambetova, Tatyana Smagliy, Saule Berdenova, Bagytzhan Alshanova, Tatyana Pchelkina, Gauhar Balgabaeva \& Saule Baizhanova contributed equally to the experimentation.

Mukhtar Tolegen, Bibikul Utegenova \& Saule Berdenova wrote and edited the article.

Botagoz Baymuhambetova, Tatyana Smagliy \& Saule Baizhanova equally designed and conducted the experiment.

Bagytzhan Alshanova, Tatyana Pchelkina \& Gauhar Balgabaeva studied scientific literature about the topic.

All authors read and approved the final manuscript.

\section{References}

1. Abil YA, Kim NP, Baymuhambetova BSh, Mamiyev NB, Li $Y D$ \& Shumeyko TS: Psychologic-pedagogical Conditions for Prevention of Suicidal Tendencies among Teenagers. Int J Sci Educ 2016; 11:4954-66

2. Barratt ES, Stanford MS, Dowdy L, Liebman MJ \& Kent TA: Impulsive and premeditated aggression: a factor analysis of selfreported acts. Psychiat Res 1999; 86:163-73

3. Beck AT, Ward CH, Mendelson M, Mock J \& Erbaugh J: An inventory for measuring depression. Arch Gen Psychiat 1961; 4:561-71

4. Bell J, Stanley N, Mallon $S \&$ Manthorpe J: The role of perfectionism in student suicide: three case studies from the UK. Omega (Westport) 2010; 61:251-67

5. Bertolote JM, Fleischmann A, De Leo D, Bolhari J, Botega N, De Silva D, et al.: Suicide attempts, plans and ideation in culturally diverse sites: the WHO SUPREMISS community survey. Psychol Med 2005; 35:1457-65

6. Cash SJ \& Bridge JA: Epidemiology of Youth Suicide and Suicidal Behavior. Curr Opin Pediatr 2009; 21:613-9

7. Cramer RJ, La Guardia AC, Bryson C \& Morgan K: The intersection of nonsuicidal self-injury and suicide-related behavior: Patterns of elevated risk and implications for college mental health. J Am Coll Health 2017; 65:363-71

8. Delara $M$ \& Woodgate RL: Psychological distress and its correlates among university students: a cross-sectional study. J Pediatr Adol Gynec 2015; 28:240-4

9. Durkee T, Hadlaczky $G$, Westerlund $M \&$ Carli V: Internet pathways in suicidality: a review of the evidence. Int $J$ Environ Res Public Health 2011; 8:3938-52

10. Eaton DK, Kann L, Kinchen S, Shanklin S, Ross J, Hawkins J, et al.: Youth risk behavior surveillance - United States, 2009. MMWR Surveill Summ 2010; 59:1-142 
11. Fazal F, Chaudhry AG, Ahmed A, Aurangzeb Chohan M, Hussain $S$ \& Khurum Irshad M: Social institutions and suicidal behaviors among university students: a study of opinion evaluation of university graduates on depressive disorders in Islamabad. Sci Int 2012; 24:167-9

12. Gençöz T\& Or P: Associated Factors of Suicide Among University Students: Importance of Family Environment. Contemp Fam Ther 2006; 28:261-8

13. Goldblum P, Dorothy L, Espelage DL, Chu J \& Bongar B. Youth Suicide and Bullying: Challenges and Strategies for Prevention and Intervention. Oxford University Press, New York, 2015

14. Hamilton TK \& Schweitzer RD: The cost of being perfect: perfectionism and suicide ideation in university students. Aust NZ J Psychiat 2000; 34:829-35

15. Hewitt PL, Flett GL, Sherry SB \& Caelian C: Trait perfectionism dimensions and suicidal behavior. In Ellis TE (ed): Cognition and suicide: Theory, research, and therapy, 215-235. APA Books, Washington, DC, 2006

16. Holmes TH \& Rahe RH: The Social Readjustment Rating Scale. J Psychosom Res 1967; 11:213-8

17. Information and legal system of regulatory legal acts of the Republic of Kazakhstan: State program for the development of education and science in the Republic of Kazakhstan for 2020-2025, 2019. http://adilet.zan.kz/rus/docs/P1900000988

18. Kholmogorova AB, Garanyan NG, Gorshkova DA \& Melnik AM: Suicidal behavior among the student population. Cultural-historical psychology 2009; 1:101-10

19. Leonhard K: Accented Persons - Akzentuierte Persönlichkeiten (German ed.). Fischer, Berlin, 1976

20. Linehan MM: Suicidal Behaviors Questionnaire (Unpublished manuscript). Department of Psychology, University of Washington, Seattle, WA, 1996

21. Loftis M, Michael T\& Luke Ch: College Student Suicide Risk: The Relationship between Alexithymia, Impulsivity, and Internal Locus of Control. Int J Educ Psychol 2019; 8:246-69

22. Messias E, Castro J, Saini A, Usman M \& Peeples D: Sadness, suicide, and their association with video game and internet overuse among teens: results from the youth risk behavior survey 2007 and 2009. Suicide Life Threat Behav 2011; 41:307-15

23. Moos RH \& Moos BS: Family environment scale manual (2nd ed.). Consulting Psychologists Press, Palo Alto, CA, 1986

24. Myrzakhanova IA, Sadykova AE \& Sovetkanova DM: The role of the teacher in the development of the intellectual and creative potential of youth. Int J Exp Educ 2014; 3:35-9

25. Nuriev MA, Seisenbaeva JA, Myrzakhanova IA \& Sadykova $A E$ : The theoretical foundations of the formation of an intellectual nation of research. Basic Res. 2013; 4:443-7
26. Nusenova TZh: Life imperative of modern student youth of Kazakhstan. Materials of the IV International Student Scientific Conference "Student Scientific Forum". Publishing House of the Academy of Natural Sciences, Moscow, 2012

27. Peltzer K, Yi S \& Pengpid S: Suicidal behaviors and associated factors among university students in six countries in the Association of Southeast Asian Nations (ASEAN). Asian J Psychiatr 2017; 26:32-8

28. Perez-Brumer A, Day JK, Russell ST \& Hatzenbuehler ML: Prevalence and Correlates of Suicidal Ideation among Transgender Youth in California: Findings from a Representative, Population-Based Sample of High School Students. J Am Acad Child Psy 2017; 56:739-46

29. Plutchik R, Kellerman $H \&$ Conte HR: A structural theory of ego defences and emotions. In Izard CE (ed): Emotions in personality and psychopathology, 229-257. Plenum Press, New York, 1979

30. Poorolajal J, Panahi S, Ghaleiha A, Jalili E \& Darvishi $N$ : Suicide and Associated Risk Factors Among College Students. Int J Epidemiol Res 2017; 4:245-50

31. Sacharewicz A \& Maciorkowska E: The knowledge of pedagogic students on suicidal behaviors in adolescents. Rocz Akad Med Bialymst 2005; 50:276-9

32. Said D, Kypri $K \&$ Bowman J: Risk factors for mental disorder among university students in Australia: findings from a web-based cross-sectional survey. Soc Psych Psych Epid 2013; 48:935-44

33. Tang $F \&$ Qin P: Influence of personal social network and coping skills on risk for suicidal ideation in Chinese university students. PLoS One 2015; 10:e0121023

34. Vahia IV, Chattillion E, Kavirajan $H$ \& Depp CA: Psychological protective factors across the lifespan: implications for psychiatry. Psychiatr Clin North Am 2011; 34:231-48

35. Wang L, He CZ, Yu YM, Qiu XH, Yang XX, Qiao ZX, et al.: Associations between impulsivity, aggression, and suicide in Chinese college students. BMC Public Health 2014; 14:551

36. Ware JE, Snow KK, Kosinski M \& Gandek B: SF-36 Health Status Survey: Manual and interpretation guide. The Health Institute, New England Medical Center, Boston, 1993

37. Wasserman D, Cheng $Q$ \& Jiang GX: Global suicide rates among young people aged 15-19. World Psychiatry 2005; 4:114-20

38. Young KS: Internet addiction: The emergence of a new clinical disorder. CyberPsychol Behav 1998; 1:237-44

39. Zimmerman GM, Rees C, Posick C \& Zimmerman LA: The power of (Mis)perception: Rethinking suicide contagion in youth friendship networks. Soc Sci Med 2016; 157:31-8

40. Zung $W W:$ A rating instrument for anxiety disorders. Psychosomatics 1971; 12:371-9

Correspondence:

Mukhtar Tolegen, MD

East Kazakhstan State University named after S. Amanzholova

30th Guards Division St., 34, Ust-Kamenogorsk, 70020, Kazakhstan

E-mail: tolegenmukhtar@rambler.ru 